\title{
Interfaces telemáticas: linguagens e interação na construção de momentos comunicativos ${ }^{1}$
}

\author{
Beatriz Bretas ${ }^{2}$ \\ UFMG \\ beatrizbretas@uol.com.br \\ Rafael Figueiredo Cruz e Silva3 \\ UFMG \\ rcruzesilva@yahoo.com.br
}

\begin{abstract}
Resumo: Tendo em vista a Comunicação Mediada por Computador (CMC), o artigo parte da noção de interface, analisada como base material de inscrição de mensagens e como espaço de interações comunicativas, compreendidas à luz do Interacionismo Simbólico. Discorre sobre a sociabilidade, compreendida como um tipo de interação específico, para estudar as interações telemáticas configuradas por quadros enunciativos de comunidade virtuais. Tomando um espaço de relacionamentos na web onde ocorrem interações desse tipo - o "Orkut" - volta-se para a análise de enunciados expressos por participantes da comunidade da banda Pearl Jam, buscando a reconstituição de momentos comunicativos possibilitados pelas interfaces.
\end{abstract}

Palavras-chave: interação - sociabilidade - Comunicação Mediada por Computador (CMC)

\begin{abstract}
In view of Computer Mediated Communications (CMC), the article starts with the notion of interface, understood as material basis for the inscription of messages and as a space for communicational interactions, according to Symbolic Interactionism. It discourses on sociability, understood as a specific form of interaction, to study the online interactions that are configured by virtual community-type frameoworks. By approaching an online relational space where such interactions take place - the website "Orkut" - the article turns to the analisys of statements made by members of a community focusing on the band Pearl Jam, trying to reconstruct coomunicational moments made possible by the interfaces.
\end{abstract}

Key-words: Interaction - Sociability - Computer Mediated Communication $(C M C)$.

1 Trabalho apresentado ao Grupo de Trabalho "Comunicação e Sociabilidade", do XV Encontro da Compós, na Unesp, Bauru, SP, em junho de 2006.

2 Professora do Programa de Pós-Graduação em Comunicação Social /UFMG. Bolsista de Produtividade em Pesquisa do CNPq.

3 Aluno do Mestrado do Programa de Pós Graduação em Comunicação Social /UFMG. Bolsista da Capes. 
Resumé: Dans le champ d'étude de la Communication Médiatisée par Ordinateur (CMO), ce travail s'organise autour du concept d'interface, pris ici comme base matérielle d'inscription de messages et comme espace d'interactions communicatives. Il parle de la sociabilité, comprise comme un type d'interaction spécifique pour étudier les interactions télématiques conformées par les cadres énonciatifs des communautés virtuelles. Dans un espace de rapports dans la Web où se passent ces interactions - le «Orkut »on se propose d'analyser les énoncés des participants de la communauté du groupe Pearl Jam, tout en essayant de reconstruire les situations communicatives possibilités par les interfaces.

Mots-clés: interaction - sociabilité - Communication Médiatisée par l'Ordinateur

Resumen: Teniendo en cuenta la Comunicación Mediada por Computadora $(C M C)$, el artículo parte de la noción de interfaz, analizada como base material de inscripción de mensajes y como espacio de interacciones comunicativas, comprendidas a la luz de la Interacción Simbólica. Trata de la sociabilidad, comprendida como un tipo de interacción específico, para estudiar las interacciones telemáticas configuradas por cuadros enunciativos de comunidades virtuales. Tomando un espacio de relaciones en la web donde ocurren interacciones de este tipo -"Orkut" - se vuelca al análisis de enunciados expresados por integrantes de la comunidad del conjunto Pearl Jam, buscando la reconstitución de momentos comunicativos posibilitados por las interfaces.

Palabras-clave: Interacción - Sociabilidad - Comunicación Mediada por Computadora (CMC).

\section{Introdução}

Este trabalho resulta de reflexões elaboradas no projeto de pesquisa "Interfaces telemáticas: sujeitos na atualização do virtual”, que toma como objeto de estudo processos interacionais envolvendo a comunicação mediada por computador (CMC) ${ }^{4}$. Trata-se de perceber processos de produção de sentido em espaços de visibilidade pública na Internet, marcados pela interlocução de vários atores. Leitores e produtores de mensagens são aí compreendidos como sujeitos em interação. A pesquisa almeja, também, compreender modos operatórios de processos colaborativos produzidos por interações

\footnotetext{
${ }^{4}$ Pesquisa desenvolvida no GRIS - Grupo de Pesquisa em Imagem e Sociabilidade da UFMG, dentro do projeto integrado "Narrativas do cotidiano: os sujeitos nas interfaces".
} 
comunicativas na rede, focando e analisando fenômenos gerados por ações cooperativas em espaços de sociabilidade.

Empiricamente, no âmbito da CMC, partimos à procura de espaços de interlocução na web que configurassem narrativas e ações dentro e fora da rede. Trata-se de olhar para diferentes práticas discursivas ambientadas na Internet, tendo em vista a ação dos sujeitos nas interfaces. Ou seja, tentamos perceber a dimensão da linguagem produzindo intervenções na dimensão situacional, ou na "realidade extralingüística" (CHARAUDEAU, 1996:8) dos atores que se encontram interagindo. O material bruto recolhido para a análise constitui-se de registros de processos comunicacionais operados dentro de comunidades de enunciadores na Internet. Esboçamos aí uma tentativa de flagrar tais processos, categorizando seus elementos de linguagem, estabelecendo tipologias de interlocutores e buscando padrões e singularidades, para perceber fios narrativos construídos por enunciados e enunciações. A possibilidade de armazenar esses dados digitalizados, compreendendo também as próprias interfaces gráficas que dão suporte à publicação de mensagens, viabiliza, ainda, a construção de bancos de dados informatizados. Dessa maneira, viabilizamos o processamento de grandes conjuntos de mensagens, fornecendo índices para a análise qualitativa do material coletado.

Nesta reflexão procuramos delinear a noção de interface com vistas a circunscrever os processos comunicativos focados, incorporando outras noções basais e correlatas, para, então, tomar um recorte de um quadro enunciativo ${ }^{5}$ de uma comunidade virtual de enunciadores e operá-lo analiticamente com essas idéias.

\section{Sentidos de interface}

A idéia de interface parece própria das esferas informáticas. As interfaces gráficas dos computadores foram, em grande parte, responsáveis por torná-los amigáveis, facilitando o manuseio de ferramentas e aplicativos. As telas dos computadores passaram a utilizar imagens, além de textos e caracteres. As ferramentas passaram a contar com janelas,

\footnotetext{
${ }^{5}$ A concepção de quadro enunciativo designa uma série de componentes utilizados para conferir significação aos enunciados; tais componentes em articulação destacam evidências que permitem aos interlocutores compartilharem os sentidos. (RODRIGUES, 1999).
} 
ícones e botões para provocar usos intuitivos. No computador as interfaces evocam metáforas para tornar suportável nosso contato com uma infinidade de zeros e uns e com as linguagens que colocam a máquina em operação (JOHNSON, 2001). Os signos codificados nessas superfícies são tecidos em bytes.

O usuário comum detém apenas parte do código ${ }^{6}$ que se materializa em textos, sejam eles compostos de escritas alfabéticas, linguagens icônicas ou sonoras, operando com as alternativas permitidas pelo software. Isso corresponde à lógica estabelecida pela interface que "atua como uma espécie de tradutor, mediando entre as duas partes, tornando uma sensível para a outra" (JOHNSON, 2001:17).

Do ponto de vista material ou tangível, a idéia de interface está relacionada aos dispositivos $^{7}$ que possibilitam a manifestação de enunciados e de enunciações. $O$ enunciado é entendido como unidade do discurso. É o que resulta da enunciação ou ato que produz sentido. A enunciação apresenta um caráter peculiar e único, diferente do enunciado, que pode ser repetido. $O$ enunciado não necessariamente refere-se a uma unidade verbal e pode traduzir-se até pelo silêncio (RODRIGUES, 1999).

Dando complexidade à noção de interface, extrapolamos o mundo físico das máquinas em conexão para pensarmos na produção de sentido resultante de enunciados e enunciações públicas na web. Interfaces são construídas de materiais significantes e prestam-se a participar da produção de sentido em prol da ocorrência de interações. É possível dizer que as interfaces dos processos comunicativos estão, por natureza, inseparavelmente ligadas aos dispositivos que participam de sua conformação.

Partindo de uma de suas acepções dicionarizadas, distinguimos o termo "interface" como "área em que coisas diversas (dois departamentos, duas ciências etc.) interagem", o que aponta para uma dimensão do espaço e do tempo na qual uma ação (encontro) ocorre. Mas o encontro seria apenas o primeiro passo para um processo mais complexo, pois os

\footnotetext{
${ }^{6}$ A idéia de código refere-se a "... um sistema de convenções comunicativas que constituem regras de uso e organização de vários significantes" (ECO, p.372)

7 Os "dispositivos" são entendidos como entidades técnicas que não se apartam do sentido, ou que não dicotomizam o continente e o conteúdo (MOUILLAUD, 1997).

${ }^{8}$ Dicionários Houaiss da Lingua Portuguesa (versão online). Disponível em http://houaiss.uol.com.br/busca.jhtm?verbete=interface .
} 
dois (ou mais) se encontram e interagem. A noção de interação aqui é bastante própria para indicar o tipo de encontro que marca a interface como um momento (definido no espaçotempo) de compartilhamento simbólico. Assim, interfaces também podem ser entendidas como superfícies ou zonas que permitem contatos ou ligações. Constituem-se como algo que é construído pelos sujeitos interagentes nos atos comunicativos, possibilitando a produção, a percepção e a interpretação de mensagens que se inscrevem nesses lugares. As interfaces são próprias de todas as situações comunicativas e são também condições para que essas situações se realizem. São pré-condicionadas por uma série de fatores de ordens diversas (natureza do suporte, tempo, espaço, custos etc) que, no entanto, não conseguem determinar integralmente as interações produzidas.

As interfaces materiais demandam leituras, compreendidas como ações de sujeitos na atribuição de sentidos às mensagens corporificadas por linguagens, abrangendo a interpretação e a compreensão de textos. Estes processos são marcados, também, pela compreensão do contexto histórico-social que abriga a sua produção, articulando a intertextualidade de discursos lingüísticos com discursos em outros códigos. A leitura é um trabalho de atualização de enunciados virtuais que se transformam em enunciações ao serem apreendidos pelos sujeitos nas interações.

Propomos, então, a estudar a interface a partir de suas características imateriais e materiais: de um lado é vista como espaço do encontro de consciências (DUARTE, 2003); de outro é compreendida como base material de inscrição de mensagens. Em ambas as direções, há sempre um material subjetivo que ocupa territórios simbólicos ou concretos; arregimentam signos em variados códigos de linguagem e marcam a ocorrência das interações. Os elementos significantes das interfaces podem ser compreendidos como textos tecidos nesses códigos, cuja decodificação demanda repertórios comuns entre os sujeitos que participam dos processos de interlocução.

A idéia de interação é central nos dois direcionamentos, o que solicita uma discussão específica. Ou seja, a partir de uma interface material (que estrutura elementos significantes de linguagem) pretendemos alcançar a configuração da zona de encontro e 
interação dos interlocutores para extrairmos possíveis sentidos produzidos nas enunciações.

\section{Interação, interface e sociabilidade}

Buscamos o conceito de interação na perspectiva teórica consubstanciada pelo Interacionismo Simbólico, desenvolvida nos Estados Unidos no início do século XX. A partir desta tradição, na qual se destaca o psicólogo social G. H. Mead, a interação pode ser definida como ação reciprocamente referenciada. Em outras palavras, nos referenciamos a partir do comportamento do outro. Num diálogo, por exemplo, muitas vezes só temos a consciência de que fizemos um comentário impertinente a partir do momento que o nosso interlocutor manifesta desagrado. Ou seja, é a partir da ação do outro que balizamos nosso comportamento e assim também é com ele. De acordo com Mead (1934), nós estamos, mais ou menos inconscientemente, nos vendo como os outros nos vêem. Estamos criando um estereótipo nosso, como os outros criam para nós. Estamos chamando no outro algo que chamamos em nós mesmos, e assim, tomamos estas atitudes. Estamos, inconscientemente, nos colocando no lugar dos outros e agindo como os outros agiriam, ajustando nossos atos ao dos outros. A interação seria, assim, o ajustamento dos atos dos interagentes dentro do processo social.

Porém, esta interação só é possível porque os interlocutores compartilham um mesmo código, ou linguagem. A linguagem é condição fundamental para que a interação seja possível, pois é através dela que damos sentido às ações e reações dos nossos interlocutores:

“... [in social interaction, we] have a symbol which answers to a meaning in the experience of the first individual and which also calls out that meaning in the second individual. Where the gesture reaches that situation it has become what we call 'language'. It is now a significant symbol and it signifies a certain meaning". (MEAD; 1934: 46)9.

\footnotetext{
9 “... [na interação social, nós] temos um símbolo que está ligado a um significado de acordo com a experiência do primeiro indivíduo e que invoca esse significado no segundo indivíduo. Quando o gesto alcança esta situação, ele se transforma no que chamamos 'linguagem'. Ele é, assim, um símbolo significante e ele está ligado a um certo sentido".
} 
O simples encontro dos interlocutores não é suficiente para que haja comunicação: eles precisam estar em interação. É a interação que constitui o momento da ocorrência da comunicação. É no momento que há ação e reação, baseada na linguagem, que a relação realmente acontece e se efetiva. Este é o momento da interface - zona de compartilhamento de sentido; aí acontece a comunicação.

A comunicação assim concebida torna-se totalmente contrária a uma concepção bipolar do processo comunicativo. A comunicação acontece num terceiro momento durante a efetuação do encontro. E este terceiro momento não é o mesmo nem da emissão nem da recepção, e nem uma simples adição dos dois. De acordo com Eduardo Duarte (2003), “... na comunicação, entre mim e o outro, ambos são arrastados para uma zona na qual perdem algo de si. Porque algo de mim passa a compor o outro, e eu passo a ser composto por algo do outro..." (DUARTE; 2003:47). Aí um novo lugar é instituído, uma zona intermediária, que é conformada pela interação.

Este novo território, gerado pelo encontro, representa o "momento comunicativo", o ato dialógico ou o processo em si. Recorrendo a David Bohm, assim Duarte explica as condições para a ocorrência do diálogo:

“...o diálogo só é possível a partir de uma suspensão, por mínima que seja, das estruturas tácitas de conceitos e idéias que cada consciência traz. Com essa suspensão, o plano cognitivo do outro pode se fazer presente no meu plano cognitivo, formando um terceiro campo cognitivo que não estava presente antes do encontro. [...] essa é outra característica da comunicação: ela não existe antes das consciências envolvidas se encontrarem. Ela é um terceiro plano cognitivo que emerge e que não estava contida inicialmente nos planos de nenhuma das partes, mas se construiu pela desterritorialização das partes que reterritorializaram um terceiro cogito emergente. A comunicação então é uma virtualidade que se atualiza na relação" (DUARTE: 2003; 47-48).

Duarte entende que o lugar desse acoplamento de planos dimensiona “...uma fronteira criativa de novas formas cognitivas" (DUARTE, 2003:50) e configura um espaço de interface no tempo da interação. O "momento comunicativo" estabelecido entre dois interlocutores é construído no instante da interação, conformado pela relação estabelecida entre os que interagem. É o momento da interface. Essa noção se torna um interessante operador analítico para percebermos fenômenos comunicativos 
Nossa pesquisa exige um esforço de captura do momento comunicativo, ou o momento da interface, para tentarmos circunscrever as interações. Nosso exercício é, portanto, estabelecer uma superfície, um mapa, para então reconstituir a interação que aconteceu ali e visualizar suas possíveis resultantes, numa tentativa de identificar e compreender o movimento dos atores naquele momento específico.

A tarefa é registrar o momento, o palco e a cena social para reconstituir e compreender as interações comunicativas que ali aconteceram, mesmo entendendo que natureza fugidia e volátil da enunciação nos permite apenas aproximações da realidade e não a integralidade do sentido produzido nesses processos, incapaz de ser apreendida na sua completude. Obviamente, não queremos afirmar que apenas o momento comunicativo ali estabelecido é suficiente para explicar todo o processo. Não podemos perder de vista que as interações cotidianas estão mergulhadas em diversos contextos que as influenciam. Pelo contrário, queremos destacar a força e importância destes diversos contextos na constituição das interações. Nessa concepção, a zona de interface só existe na ocasião em que os interlocutores se encontram e passam a estabelecer um processo interativo. E deixa de existir quando os interlocutores se separam.

$\mathrm{Na}$ perspectiva do Interacionismo Simbólico, mais do que um grande coletivo de pessoas, o conceito de sociedade designa pessoas em interação. A estrutura social só existe porque as pessoas estão se relacionando, interagindo, comunicando. Um tipo de interação bastante importante para entendermos os processos comunicativos é a sociabilidade. Para Simmel (1983), a sociabilidade seria uma forma pura ou espontânea de interação responsável pela geração dos processos de sociação, fazendo referência à força que une os indivíduos, a uma forma de relação social que existe para manter os laços sociais. Desvestida de interesses, a sociabilidade seria uma interação da ordem dos sentimentos, de relações de afinidade construídas entre as pessoas. Como o autor afirma “... o 'impulso de sociabilidade' extrai das realidades da vida social o puro processo de sociação como um valor apreciado, e através disso constitui a sociabilidade no sentido estrito da palavra" (SIMMEL; 1983: 169). 
A sociabilidade seria, assim, a interação responsável por manter a coesão do tecido social. A estrutura social depende dela, a partir das constatações de que em grande parte do nosso tempo estamos estabelecendo relações de sociabilidade. Quando entramos para o trabalho ou a escola e cumprimentamos nossos colegas ou quando estamos em alguma reunião social (festas, eventos), normalmente interagimos com diversas pessoas com o único objetivo de manter relações sociais. Realizamos, assim, funções fáticas da linguagem, nas quais o objetivo principal não é a transmitir informações e, sim, o estimular ou exercitar a sociabilidade e a comunicação.

Partindo da concepção simmeliana, Maffesoli (1985) também compreende a sociabilidade como momento do estar-junto, conferindo importância ao universo simbólico que envolve os indivíduos. Para ele, tal dimensão existe em potência e é atualizada na relação, no momento em que os interlocutores interagem.

Essa ambiência simbólica é incorporada na sociologia compreensiva ou qualitativa de Maffesoli, caracterizada como um método específico que pretende "acompanhar de perto os meandros da existência social. Trata-se de dar conta da vida em sociedade, da existência social em sua totalidade” (MAFFESOLI,1985:197). Enfatiza-se aí a valorização das representações e a apreensão das formas da vida social através da utilização de analogias e de metáforas. Os elementos do sensível, da ordem do fenômeno, incorporam o lúdico, o onírico e o imaginário, apontando para uma retórica da vida social expressa nos modos de convivência.

No mundo atual, tratando-se de colocar em foco as relações entre as pessoas e as diversas formas de estar junto, caracterizando sociabilidades, torna-se oportuno observar os movimentos musicais da juventude, perceber os arabescos tribais fixados perenemente no corpo dos jovens dos centros urbanos do mundo, compreender as novas congregações de fé religiosa. Essas imagens e sons fazem parte da fala do mundo e demonstram os movimentos de agregação a partir de identificações, a exemplo da tatuagem gravada no corpo, que remete a uma comunidade de consciência, representando a sociedade que age e vive em nós, tal qual formulou Durkheim (QUINTANEIRO, 1995). 
Para Maffesoli (1996), um importante vetor de conhecimento do tecido social vivo é a intuição, categoria útil e necessária para compreender as formas contemporâneas de sociabilidade. A intuição pode ser reconhecida como um "saber incorporado" (MAFFESOLI, 1996:172), um conhecimento tácito, resultado de uma experiência ancestral sedimentada que participa do inconsciente coletivo. A experiência estética que permite o sentir junto e vibrar em uníssono, produzindo uma estética da recepção, está apoiada no conhecimento intuitivo, e não no conhecimento conceitual. É onde podem ser localizadas as manifestações do tribalismo, a exemplo das agregações juvenis, regidas pela lógica da identificação.

A apreensão da vida social traz à tona o cotidiano, as coisas banais, os sentimentos, o burburinho em background dos espaços urbanos, a vida comum. O urbano re-atualiza a interação entre os indivíduos: "Redes interativas se estabelecem [...] a partir de grupos de amizade eletiva, de tribos, de relações de vizinhança em nichos microcósmicos, tornando o espaço urbano reterritorializado" (MAIA; 2002: 10).

\section{Interações nas interfaces telemáticas}

Com o advento da telemática, redes de interação social ampliaram suas dimensões conformando novos ambientes de trocas comunicacionais e de convivência social. $O$ modo gráfico da Internet, baseado em protocolo de hipertextos, produziu interfaces cujos enunciados podem ser configurados em variados códigos de linguagem (verbais, musicais, imagéticos etc). São recursos que, utilizados para estabelecer relações em determinados ambientes, dizem da vontade de estar-junto, da manutenção de relações sociais. Desde o início da apropriação popular da Internet já se tornavam evidentes os sinais de que os encontros on-line das pessoas podiam introduzir as pessoas nas redes sociais da vida, para onde a vida real (real life) e a vida virtual (virtual life - VL) se convergem (PARKS \& FLOYD, 1996) ${ }^{10}$.

Partindo do pressuposto da ocorrência de novas configurações de sociabilidade proporcionadas pela Internet, conseguimos perceber, com certa facilidade, diversas

\footnotetext{
${ }^{10} \mathrm{Em} \mathrm{http://jcmc.indiana.edu/vol1/issue4/vol1} \mathrm{no4.html}$
} 
instâncias onde este tipo de interação é estabelecida. Um destes locais, que se tornou fenômeno entre os brasileiros, é o "Orkut".

Por intermédio das interfaces físicas do site verificamos que o Orkut propõe-se a ser "...uma comunidade online que conecta pessoas através de uma rede de amigos confiáveis" ${ }^{\text {"11 }}$, conformando uma rede virtual de relacionamentos, onde cada usuário possui uma página que exibe seu perfil com características diversas: nome, sexo, idade, cor, nacionalidade, cidade de origem, entre outras. Cada um pode se apresentar e travar contatos a partir de sua própria interface, ainda que regida pelas padronizações definidas pelo serviço.

O Orkut foi criado pelo cidadão turco Orkut Buyukkokten, analista de sistema responsável pelo mecanismo de buscas da Web mais utilizado na atualidade, o Google. Uma das razões para o sucesso do Orkut se deve à seguinte estratégia para participar do site, é necessário ser convidado por outro usuário já cadastrado, o que significa que cada novo participante já está, desde o momento de sua adesão, potencialmente conectado a todos os outros. Uma vez que cada participante convida outras pessoas para também participarem do site, o número de usuários cresce vertiginosamente.

Buyukkokten aplicou essa filosofia de funcionamento a um sistema de perfil pessoal baseado em permissões de acesso que incorpora aspectos de, pelo menos, outras quatro ferramentas já conhecidas entre os usuários da Internet: álbuns de fotos, blogs, comunidades virtuais e fóruns de discussões. Esse perfil pessoal é alimentado por um cadastro detalhado que, aliado à rede de relações entre os usuários e comunidades destinadas a discutir os mais diversos assuntos, permite que o Orkut construa um complexo ambiente de sociabilidade virtual (GUIMARÃES JUNIOR, 1999). Isso porque a ferramenta permite não apenas o estabelecimento de novas relações (ou o restabelecimento de antigas) com base em afinidades e interesses comuns, mas também possibilita que essas relações configurem uma intrincada rede de relacionamentos que não só é visível, como também é navegável de modo hipertextual. As informações aí são dispostas espacialmente e organizam as relações humanas da mesma forma, apresentando-as dispostas nas

${ }^{11}$ Em http://www.orkut.com . 28 de Novembro de 2005. 
interfaces gráficas. Os nós, ou links, dessa rede hipertextual são os próprios usuários; essas interfaces configuram um mapa de relações intersubjetivas.

Dentro do Orkut, nossa análise parte para uma comunidade virtual ali instalada: a da banda norte-americana Pearl Jam. A banda de rock, que surgiu início dos anos 90, identifica-se com o movimento grunge ${ }^{12}$ de Seattle. Neste movimento, que surgiu como uma crítica à mercantilização das bandas de hard rock do cenário norte-americano, foi criada uma nova safra de bandas de rock nos Estados Unidos (entre as quais se destacam o Nirvana, Soundgarden e Alice in Chains) que refletiam um certo pessimismo em suas músicas.

O Pearl Jam se apresentou no Brasil pela primeira vez (no final de 2005, com shows em Porto Alegre, Curitiba, São Paulo e Rio de Janeiro) e um dos principais motivos alegados pela banda para fazer apresentações no país foi o grande apelo dos fãs. Este apelo está ligado a um abaixo assinado ${ }^{13}$ com mais de 7500 assinaturas que foi organizado pelos participantes da loquaz comunidade "Pearl Jam", no Orkut. Num tópico ${ }^{15}$ criado por um dos participantes, várias pessoas se mobilizaram na tentativa de realmente trazer a banda para fazer apresentações no Brasil. Esta mobilização gerou resultados efetivos como a criação da petição on line para assinaturas de todos os interessados em trazer o Pearl Jam para o Brasil e, posteriormente, a confirmação que a banda se apresentaria no país. As interfaces gráficas da comunidade "Pearl Jam" possibilitaram que esta ocorrência fosse, então, passível de observação e suscetível de descrição, de análise e de interpretação. De acordo com Freire Filho (2005)

"paralelamente [...] à promoção do comércio e do mercado global no ciberespaço, prospera o uso de comunicação baseada no computador como plataforma para elaboração e disseminação de estratégias contra-hegemônicas no espaço físico real [...]. Sites de organizações independentes, listas de discussão e e-mails se consolidaram, ao longo dos anos 1990, como ferramentas essenciais para o estreitamento dos vínculos e o aprimoramento dos métodos de ação dos militantes, servindo para: 1) a divulgação de informações acerca das prerrogativas e atividades das instituições

\footnotetext{
${ }^{12}$ Mais informações em http://pt.wikipedia.org/wiki/Grunge .

${ }^{13}$ Disponível na web em http://www.petitiononline.com/mod perl/signed.cgi?pibrazil .

${ }^{14}$ Acessível no endereço http:/ $/$ www.orkut.com/Community.aspx? $\mathrm{cmm}=2063$.

$15 \mathrm{Um}$ tópico indica uma divisão temática dentro de um forum de discussões. O tópico referenciado é intitulado "Tá bom, vamos chamar eles pro Brasil?" e encontra-se em http://www.orkut.com/CommMsgs.aspx? $\mathrm{cmm}=2063 \&$ tid=6142622 .
} 
econômicas e corporações globalizadas (raramente discutidas, de forma crítica, na grande imprensa; 2) o intercâmbio de experiências sobre a realização de encontros e eventos; 3) a mobilização e o recrutamento em massa de indivíduos dispersos geograficamente" (FREIRE FILHO; 2005: 153).

Nosso primeiro movimento de apreensão desse fenômeno foi o de identificar e compreender os fatores que motivam essas pessoas a se encontrarem na rede, discutirem um assunto comum e estabelecer um processo colaborativo. Munido das referências trazidas por Nussbaumer (2005), quando a autora, revisando Foucault, defende que a produção da subjetividade individual se dá pela interiorização de valores e experiências vividas no social, acreditamos que os participantes da comunidade do Pearl Jam no Orkut dão validade a um mesmo conjunto de valores que, de certa forma, são compartilhados através da própria obra da banda, como podemos ver através da mensagem abaixo:

\section{3/02/2005 08:01}

Também me disponho a ajudar nesse projeto. Sou fã do Pearl Jam desde os idos de 1991 e nunca aceitei bem essa deles não tocarem aqui. Sempre pude perceber que a banda tem muitos, mas muitos fãs mesmo no Brasil... em toda parte. Um show deles provavelmente só em sampa mesmo, pois o Rio está sofrendo um esvaziamento quanto a shows (vide o ultimo tim festival). Já assimilei a idéia de ter que me deslocar para a terra da garoa pra vê-los tocar... Essa é a hora de isso se tornar realidade.... chega de bater na trave!!!! agora é gol!!! Tai... podiamos oferecer tanto pra Tim quanto pra Gol entrarem no patrocínio deste projeto. Assim como a Vivo e outras empresas com mais mídia atualmente. Todas tem sempre idéias para grandes eventos que geram possibilidades ótimas pra agregar valor as suas marcas. Por que não apoiárem a vinda de uma banda tão engajada em questões sociais/beneficientes??? Bem... o que eu queria dizer é... contem comigo aqui no Rio pra ajudar. É só me avisar de que forma. Parabéns Eduardo, Rita, Edu Salsicha e Gabriel... primeiros a tocar o projeto pra frente. Esses tem que ser homenageados no dia do Show, subindo ao palco ao lado de Eddie Vedder, na hora do bis... Valeu! (Marco)

Além disso, há de se destacar a importância de um contexto cultural comum entre os participantes da comunidade. Considerando a música um elemento cultural de agregação que promove identificações, há uma série de sentidos compartilhados entre os fãs que participam do processo de colaboração, no qual se encontra implícito uma espécie 
de contrato que baliza os comportamentos linguageiros dos interlocutores ${ }^{16}$. Como destacado por Freire Filho (2005), há nos atuais movimentos jovens novas formas de posicionamento e participação política que podem motivar ações cooperativas intermediadas pela Internet, como forma de facilitar e potencializar propostas coletivas. Os elementos de provocação e desafio, próprios do estilo grunge, desvelam aspectos ideológicos compartilhados pela comunidade Pearl Jam no Orkut, como os expressos nas notações de trechos das letras das músicas da banda que são enviadas por vários participantes, ao final de suas mensagens:

\section{6/01/2005 15:54}

[...] Tem uma menina da comunidade que está em Atlanta e ela se comunicou comigo, se dispôs a ajudar em alguma coisa e conseguiu um lugar onde dá para encontrar endereço de correspondência de pessoas, então eu achei o endereço do Eddie. Já sabem, né? Vou enfernizar a vida do cara! Vou mandar uma carta por semana falando sobre nossa origem, nosso país, nossa diversidade cultural e musical, etc., vou dar uma caprichada, colocar fotos, mandar cds, etc., pode ser que nem chegue até ele, mas alguém que tem acesso a ele vai receber e de repente, pode comentar, sei lá...qq coisa tá valendo, né? Tb vou mandar uma cópia do nosso texto do abaixo assinado com o endereço e depois que tivermos muitas assinaturas, mando uma cópia completa, ok? [...]

"I know I was born and

I know that I'll die,

the in between is mine!"

O epicentro da discussão deste tópico da comunidade do Pearl Jam no Orkut está relacionado à criação do abaixo-assinado para trazer a banda para o Brasil. Os fãs brasileiros espelharam-se no exemplo dos fãs mexicanos que, através das assinaturas no mesmo site, conseguiram que o Pearl Jam fizesse apresentações naquele país. Grande parte das mensagens do tópico está ligada ao tema do abaixo-assinado. Um dos fatores que motivou os fãs brasileiros a organizar a petição on line foi o fato da banda nunca ter vindo fazer shows no Brasil, apesar dos seus quase 15 anos de existência e do enorme número de

\footnotetext{
${ }^{16}$ Charaudeau (1996) assevera que as condições apresentadas para uma situação comunicativa são presididas por contratos de comunicação, nos quais a identificação e a explicitação de regras tornam-se tarefas para uma análise do discurso.
} 
fãs da banda no país. $\mathrm{O}$ esforço dos participantes da comunidade em promover a mobilização para a vinda da banda identifica-se com as novas maneiras de organização de movimentos sociais, nas quais a indução e a formação de redes constituem estratégias de agregação. De acordo com Freire Filho (2005):

“... as chamadas 'novas formações de protesto subcultural' se valem de modos de articulação e geração de identidades subculturais, engajando-se, contudo, em questões macro-políticas; operando, ao mesmo tempo, ideológica e hedonisticamente; compatibilizando abordagens e demandas particulares com uma dimensão de crítica e antagonismo universal" (FREIRE FILHO; 2005: 152).

O tema central da comunidade nos auxilia a visualizar o momento da interface, para o qual chamamos a atenção no início do texto. Cada mensagem da comunidade que trata do tema se referencia na anterior para apresentar sua argumentação. Um participante, ao postar uma mensagem para outro membro da comunidade, está pressupondo ali o outro. Mesmo que o diálogo não se dê de forma simultânea, o outro já se encontra presente na formulação da mensagem. Ou seja, é a referência que o participante tem do outro que baliza seu posicionamento, colocando-o diante de um outro que não está ali, "presencialmente" naquele momento, mas que existe na consciência do primeiro. Podemos ver facilmente esta auto-organização do posicionamento dos interlocutores nos exemplos abaixo:

\section{9/01/2005 19:51}

[...] Quanto ao abaixo-assinado, foi falado em fazer um abaixoassinado fora da net, mas,acredito eu, que é mais fácil fazer um pela net, pois,além de mais gente, de todos os lugares do Brasil (e pq não da América do Sul), também fica mais fácil para divulgação em sites, como o Orkut (1700o assinaturas), e sites de rock tb (Universo do Rock, Portal do rock, 89FM, Brasil 2000, entre muitos outros). Existe um site que tem a finalidade de organizar abaixo-assinados, o endereço é o seguinte:

www.petitiononline.com

Aqui vai a minha ajuda, depois eu vejo como q funciona esse site

\section{0/01/2005 18:52}

[...] Qt ao petitites.com, eu vi lá e é o seguinte: é um site que se propõe(é assim que se escreve isso?) a fazer petições on line gratuitamente, basta vc ter um pedido e lançar um abaixo-assinado, eles disponibilizam um endereço que as pessoas podem acessar, aí 
vc clica no link, entra na lista e deixa sua assinatura através de sua conta de e-mail e outros dados, esses dados não ficam disponíveis para evitar a ação de vírus, cada assinatura é representada por um número, então qd tivermos um bom número de assinaturas a lista é enviada para quem interessar possa. Parece que eles mesmos encontram essa pessoa, que deve ser, no nosso caso, assessoria(tb não sei escrever isso...)de imprensa, ou empresários.

Temos que dar um título que seja uma espécie de apelo (ou pedido...) O que vcs acham do título:

We would like to see a Pearl Jam's show in Brazil!

Ou: Please! Bring a Pearl Jam show to Brazil! [...]

\section{0/01/2005 20:13}

[...] acho q o segundo título é mais direto, traz mais atenção, entende, mas sem o "please", pois assim, fica direto demais, se é que vc entende $[\ldots]$

A partir da perspectiva assumida, podemos dizer que, com a troca de mensagens no site, os interlocutores são transportados para um “... lugar comum a partir do qual eles vão momentaneamente se relacionar uns com os outros, se relacionar com o mundo e organizar suas ações recíprocas" (QUÉRÉ: 1991; 7). E este lugar comum é a zona de interface. Nesse sentido, a comunicação que estamos tratando aqui

“... consiste então, para os agentes, em modelar em conjunto esta perspectiva comum que lhes permite configurar, conjuntamente e de maneira 'encarnada', suas intenções informativas e comunicativas respectivas, e ao mesmo tempo tornar mutuamente manifesto o que é problema entre eles [...]. Então, para o modelo praxiológico ${ }^{17}$, a comunicação é essencialmente um processo de organização de perspectivas compartilhadas...” (QUÉRÉ: 1991; 7).

\section{Arremates}

Mesmo sem apresentar idéias conclusivas acerca da ação de sujeitos nas interfaces telemáticas, podemos dizer que a breve análise do recorte empírico nos indica possibilidades de investigação de situações discursivas em contextos de comunidades virtuais, nas quais haja a marca das interações de sociabilidade. A articulação dos elementos

\footnotetext{
17 O modelo praxiológico é uma concepção do pesquisador francês Louis Quéré, baseado na obra de G. H. Mead.
} 
linguareiros nas superfícies de contato que propiciam o encontro de interlocutores dá mostras de evidências que podem ser, pormenorizadamente, examinadas.

A noção de interface, caracterizada por seus aspectos concretos e simbólicos, parece-nos, então, adequada a circunscrever delimitações para quadros enunciativos, dando condições de compreender as variadas espécies de contratos comunicativos que são estabelecidos em diferentes contextos. Um caminho a ser seguido deve compreender a verificação, a classificação e a interpretação de diversos tipos de índices dispostos em páginas da web. A tarefa consiste, assim, em dar conta de situar e entender as referências relacionais ou signos de reconhecimento das comunidades virtuais em suas conversações, tendo em vista a reconstituição de situações interativas propiciadoras de colaboração.

\section{Referências}

CHARAUDEAU, Patrick. Para uma nova análise do discurso. In: CARNEIRO, Agostinho D. (org.) O discurso da mídia. Rio de Janeiro: Oficina do Autor,1996. p. 5- 43

DUARTE, Eduardo. Por uma epistemologia da Comunicação. In: LOPES, Maria Immacolata Vassalo de (org.). Epistemologia da Comunicação. São Paulo: Edições Loyola, 2003. p.41-54

ECO, Umberto. Apocalípticos e integrados. São Paulo: Perspectiva, 1987.

GUIMARÃES JÚNIOR, Mário J. L.. Sociabilidade no ciberespaço: distinção entre plataformas e ambientes [online] Disponível na Internet em http://www.cfh.ufsc.br/ guima/papers/plat amb.html . Acesso 28/11/2005.

FREIRE FILHO, João . Das subculturas às pós-subculturas juvenis: música, estilo e ativismo político. Contemporânea, Universidade Federal da Bahia, v. 3, n. 1, p. 143-172, 2005.

JOHNSON, Steven. Cultura da interface: como o computador transforma nossa maneira de criar e comunicar. Rio de Janeiro: Jorge Zahar, 2001.

MAFFESOLI, Michel. Eloge de la raison sensible. Paris: Grasset, 1996.. 
MAFFESOLI, Michel. O conhecimento comum. São Paulo: Brasiliense, 1985.

MAIA, Rousiley C.M. Sociabilidade: apenas um conceito? Geraes -UFMG, n.53, Julho 2002 p.4-15..

MEAD, G.H. Mind, self and society. Chicago: University of Chicago Press, 1934.

MOUILLAUD, Maurice; PORTO, Sérgio Dayrell (orgs.). O jornal: da forma ao sentido. Brasília: Paralelo 15, 1997.

NUSSBAUMER, Gisele Marchiori. Sociabilidade e escrita de si em comunidades virtuais gays. Texto apresentado no GT Comunicação e Sociabilidade. Niterói. XIV Encontro Anual da Associação Nacional de Programas de PósGraduação em Comunicação - Compós, 2005.

PARKS, Malcolm R. \& FLOYD Kory, Making Friends in Cyberspace. Journal of Computer Mediated Communication [online]. v.1, n.4, 1996. Disponível na Internet em: http://jcmc.indiana.edu/vol1/issue4/parks.html. Acesso 10/05/2005.

QUÉRÉ. Louis. D'un modèle épistémologique de la communication à un modèle praxéologique. Réseaux, ${ }^{\circ}$ 46-47, mars-avril/mai-juin 1991, pp.69-90 (tradução de Lúcia Lamounier Sena e Vera Lígia Westin).

QUINTANEIRO, Tânia. Émile Durkheim. In:QUINTANEIRO, T., BARBOSA, M.L. O., OLIVEIRA, M. G. Um toque de clássicos: Durkheim, Marx e Weber. Belo Horizonte, Ed. UFMG, 1995.

RODRIGUES, Adriano. Discurso e sociabilidade. Texto apresentado no GT Comunicação e Sociabilidade. Belo Horizonte. VIII Encontro Anual da Associação Nacional de Programas de Pós-Graduação em Comunicação - Compós, 1999.

SIMMEL, Georg. Sociabilidade: um exemplo de sociologia pura ou formal.In: Moraes Filho, Evaristo de (org.). Simmel: sociologia. São Paulo: Ática, 1983. 